\title{
PARÂMETROS GENÉTICOS PARA A CAPACIDADE DE PROPAGAÇÃO DE Pinus taeda POR EMBRIOGÊNESE SOMÁTICA ${ }^{1}$
}

Poliana Coqueiro Dias ${ }^{2}$, Aloisio Xavier ${ }^{3}$, Marcos Deon Vilela de Resende ${ }^{4}$, Fabrício Antonio Biernaski ${ }^{5}$ Regiane Abjaud Estopa ${ }^{5}$

\begin{abstract}
RESUMO - Objetivou-se com este trabalho avaliar a capacidade de propagação de famílias de Pinus taeda por embriogênese somática utilizando estimativas de parâmetros genéticos. Para a embriogênese somática, foram selecionados cones imaturos de 65 famílias-elite de Pinus taeda. O germoplasma utilizado para a implantação dos testes de campo foi composto por 238 clones de 31 famílias. O estudo foi realizado por meio de análise genetíoco-estatística pelo procedimento de estimação de componentes de variância via máxima verossimilhança residual (Reml) e de predição de valores genéticos via melhor predição linear não viesada (Blup), usando-se o software Selegen-Reml/Blup. De acordo com os resultados, a variabilidade genética possibilita ganhos genéticos altos pela seleção entre famílias, para os caracteres presença de embriões somáticos e número de clones por famílias de Pinus taeda. Há baixa ou nenhuma correlação genética entre o número de clones propagados via embriogênese somática e as características altura, diâmetro, sobrevivência e volume avaliados aos 4 anos de idade em testes clonais. Conclui-se que há maior ganho genético para a capacidade de propagação por embriogênese somática com a seleção de famílias de Pinus taeda.
\end{abstract}

Palavras-chave: Controle genético; Ganho genético; Propagação clonal.

\section{GENETIC PARAMETERS FOR PROPAGATION CAPACITY OF Pinus taeda BY SOMATIC EMBRYOGENESIS}

\begin{abstract}
The objective of this work was to evaluate families propagation of Pinus taeda by somatic embryogenesis using estimates of genetic parameters. For somatic embryogenesis, immature cones of 65 elite families of loblolly pine were selected. The germoplasm used for field test was composed of 238 clones from 31 families, propagated via somatic embryogenesis. Genetic and statistical analyses were performed by estimation of variance components via residual maximum likelihood (Reml) and prediction of breeding values via best linear unbiased prediction (Blup) using the Selegen-Reml/Blup software. According to the results, genetic variability detected enables high possibility of genetic gain by selection among families, for both characters presence of somatic embryos and number of clones by families of Pinus taeda designed to somatic embryogenesis. There is little or no genetic correlation between the number of clones propagated via somatic embryogenesis and characteristics height, diameter, volume assessed and survival at four years of age in clonal tests. We conclude that there is greater genetic gain the ability to spread by somatic embryogenesis by selecting families of Pinus taeda.

Keywords: Genetic control; Genetic improvement; Clonal propagation.
\end{abstract}

\footnotetext{
${ }^{1}$ Recebido em 24.04.2014 aceito para publicação em 29.10.2015.

${ }^{2}$ Universidade Federal Rural do Semi-Árido, Departamento de Ciência Vegetal, Mossoró, RN - Brasil. E-mail: <policoqueiro@yahoo.com.br>.

${ }^{3}$ Universidade Federal de Viçosa, Centro de Ciências Agrárias, Departamento de Engenharia Florestal, Viçosa, MG - Brasil. E-mail: <xavier@ufv.br>.

${ }^{4}$ Empresa Brasileira de Pesquisa Agropecuária, Centro Nacional de Pesquisa de Florestas, Colombo, PR - Brasil. E-mail: $<$ marcos.deon@gamil.com>.

${ }^{5}$ Klabin S.A, Telêmaco Borba, PR - Brasil. E-mail: < fbiernaski@klabin.com.br> e <restopa@klabin.com.br>.
} 


\section{INTRODUÇÃO}

As técnicas de propagação vegetativa via estaquia e miniestaquia, tradicionalmente utilizadas pelas empresas florestais na clonagem de Eucalyptus, apresentam baixa aplicabilidade para Pinus, decorrente das limitações impostas pela idade da planta-matriz (ALCANTARA etal., 2007, 2008; ANDREJOW; HIGA, 2009; MALABADI et al., 2011; WAHID et al., 2012), inviabilizando a utilização de clones em escala comercial (PULLMAN et al., 2003, 2011). Como alternativa, a embriogênese somática, a partir de sementes imaturas, tem sido desenvolvida e utilizada na clonagem de Pinus taeda (PULLMAN et al., 2006; ALCANTARA et al., 2008; ANDREJOW et al., 2009; PULLMAN; BUCALO, 2011).

Em comparação com outros sistemas de propagação, utilizados para espécies florestais, como estaquia e miniestaquia, a embriogênese somática oferece as vantagens de armazenamento de tecido embrionário por longos períodos, mediante o uso da criopreservação, sem perda da juvenilidade ou interferência na propagação dos genótipos (CYR et al., 1994; PARK et al., 1998; BENOWICZetal., 2002; SUTTON, 2002; GROSSNICKLE; FOLK, 2005; MALABADI et al., 2011), além da perspectiva de manipulação automática de embriões somáticos (DEAN, 2008).

A embriogênese somática é técnica promissora para implementar a silvicultura clonal de Pinus taeda. No entanto, alguns fatores têm limitado a comercialização de embriões somáticos dessa espécie, incluindo a frequência de iniciação de culturas embriogênicas, que é altamente variável entre as famílias; a recalcitrância de alguns genótipos; a baixa sobrevivência da cultura, resultando em pouca ou nenhuma produção de embriões; e a incapacidade dos embriões somáticos em atingir a plena maturidade, resultando em baixa germinação e reduzido vigor das plântulas (PULLMAN et al., 2003). Entretanto, os protocolos visando à indução da embriogênese somática com máxima produção de plantas, reduzido custo e trabalho estão constantemente sendo revistos e melhorados (WALTER et al., 2006; PULLMAN et al., 2011).

A integração da embriogênese somática em programas convencionais de melhoramento genético permite a propagação de indivíduos com alto valor genético (PARK et al., 1998; O'NEILLLet al., 2005; DEAN, 2008). A embriogênese somática, aliada à criopreservação, tem permitido o armazenamento de linhas clonais embriogênicas, enquanto as árvores correspondentes são testadas no campo. Essa tecnologia tem permitido o desenvolvimento de clones por meio do resgate dos embriões somáticos criopreservados que mostraram superioridade genética nos testes clonais de campo (PARK, 2002; MACKAY et al., 2006).

A embriogênese somática de algumas espécies de Pinus de importância econômica chegou ao estágio de aplicação na propagação vegetativa destinada a testes clonais e seleção de genótipos superiores (WALTER et al., 2006). Testes clonais bem estabelecidos e projetados são fundamentais para o sucesso de qualquer programa de melhoramento genético, usando clones propagados via embriogênese somática, permitindo estimativa precisa de parâmetros genéticos como herdabilidade, variações genéticas e correlações e, assim, aumentar a confiabilidade com que o desempenho clonal pode ser previsto (DEAN, 2008; WAHID et al., 2012). Entretanto, poucos estudos têm sido realizados para estimar parâmetros genéticos de clones propagados via embriogênese somática em ensaios de campo(O'NEILLLet al., 2005; DEAN, 2008; BALTUNIS et al., 2008; WAHID et al., 2012).

Diante do exposto, objetivou-se com este trabalho avaliar o controle genético e a capacidade de propagação de famílias de Pinus taeda por embriogênese somática, utilizando estimativas de parâmetros genéticos, bem como realizar a correlação genética entre essas características de propagação e as características de crescimento das plantas aos quatro anos após o plantio em campo.

\section{MATERIAL E MÉTODOS}

\section{1. Área experimental e germoplasma utilizado}

O estudo foi realizado por meio de análise genetícoestatística da capacidade de produção de embriões somáticos originados de 65 famílias de Pinus taeda. Foram propagados via embriogênese somática 238 clones originados de 31 famílias (Tabela 1).

A princípio, 65 famílias-elite em testes de primeira (famílias de polinização livre) e segunda fase (famílias de polinização controlada) foram selecionadas e seus cones imaturos, coletados e transferidos para propagação via embriogênese somática. Por meio dos embriões zigóticos imaturos, foram obtidos embriões somáticos individualizados por planta, em 31 das 65 famílias enviadas 
para a embriogênese somática. O número de clones propagados em cada família foi obtido observandose o número de clones disponíveis para os testes de campo.

Os testes clonais foram implantados nos Estados do Paraná, com localização geográfica nas coordenadas $24^{\circ} 22^{\prime} 20^{\prime \prime S}$ e $50^{\circ} 38^{\prime} 24^{\prime \prime W}$ no sítio 3 e $24^{\circ} 19^{\prime} 50^{\prime \prime} \mathrm{S}$ e

Tabela 1 - Relação das famílias (entre 65 enviadas para Embriogênese Somática) de Pinus taeda que apresentaram clones propagados via embriogênese somática, com o tipo de polinização (controlada ou livre) e o número de clones propagados pela embriogênese somática.

Table 1 - Families (among 65 sent to Somatic embryogenesis) showeing Pinus taeda clones propagated via somatic embryogenesis, with the kind of pollination (controlled or open) as well the number of clones, propagated through somatic embryogenesis.

\begin{tabular}{|c|c|c|}
\hline Famílias & Número de clones & Polinização \\
\hline 1 & 15 & Controlada \\
\hline 2 & 10 & Controlada \\
\hline 3 & 7 & Controlada \\
\hline 4 & 11 & Controlada \\
\hline 5 & 1 & Controlada \\
\hline 6 & 14 & Controlada \\
\hline 7 & 4 & Controlada \\
\hline 8 & 21 & Controlada \\
\hline 9 & 2 & Controlada \\
\hline 10 & 1 & Controlada \\
\hline 11 & 33 & Controlada \\
\hline 12 & 12 & Controlada \\
\hline 13 & 10 & Controlada \\
\hline 14 & 1 & Controlada \\
\hline 15 & 1 & Controlada \\
\hline 16 & 1 & Controlada \\
\hline 17 & 8 & Controlada \\
\hline 18 & 1 & Controlada \\
\hline 19 & 2 & Controlada \\
\hline 20 & 3 & Livre \\
\hline 21 & 5 & Livre \\
\hline 22 & 5 & Livre \\
\hline 23 & 4 & Livre \\
\hline 24 & 17 & Controlada \\
\hline 25 & 35 & Livre \\
\hline 26 & 2 & Livre \\
\hline 27 & 1 & Livre \\
\hline 28 & 1 & Livre \\
\hline 29 & 1 & Livre \\
\hline 30 & 1 & Livre \\
\hline 31 & 8 & Controlada \\
\hline
\end{tabular}

Famílias enviadas para embriogênese somática: 65 Famílias com clones propagados via embriogênese somática: 31 Número total de clones: 238 $50^{\circ} 19^{\prime} 47^{\prime \prime} \mathrm{W}$ no sítio 4; e de Santa Catarina, com localização geográfica nas coordenadas $27^{\circ} 27^{\prime} 16^{\prime \prime} \mathrm{S}$ e $50^{\circ} 06^{\circ} 05^{\prime \prime} \mathrm{W}$ no sítio 1 e $27^{\circ} 32^{\prime} 58^{\prime \prime} \mathrm{S}$ e $50^{\circ} 10^{\circ} 26^{\prime \prime} \mathrm{W}$ no sítio 2, em 2007. O delineamento experimental foi o de blocos incompletos, com espaçamento de $3 \mathrm{~m}$ x $2 \mathrm{~m}$, com uma planta por parcela, em quatro locais (sítios), sendo dois em Santa Catarina e dois no Paraná. Cada sítio foi dividido em dois experimentos, mesmo estando em um mesmo ambiente, em razão do grande número de clones e da área ocupada pelos blocos. O número de blocos e os clones avaliados variaram de acordo com o experimento. Como testemunha comparativa, foram utilizados três lotes de mudas comerciais.

Segundo a classificação climática de Köppen, a região do Estado de Santa Catarina onde estão localizados os sítios 1 e 2 caracteriza-se como Cfb (KLABIN, 2009), e a área do Estado do Paraná onde estão alocados os sítios 3 e 4 encontra-se em uma região de transição climática entre Cfa e Cfb (KLABIN, 2011). Os sítios 1 e 2 apresentam temperaturas médias inferiores e maior número de geadas do que os sítios 3 e 4 , sendo a temperatura mínima nos sítios 1 e 2 de $-9{ }^{\circ} \mathrm{C} \operatorname{com} 22$ geadas em média por ano e, nos sítios 2 e 3 , temperatura mínima de $-4,5^{\circ} \mathrm{C}$ e seis geadas por ano.

\subsection{Coleta de dados}

Os dados das estimativas de parâmetros genotípicos das características relativas à capacidade de propagação por embriogênese somática (família com embriões somáticos e número de clones em cada família) foram tomados, considerando-se família com embrião somático, em razão das famílias enviadas para embriogênese somática, as quais produziram ou não embriões. Entretanto, para a característica número de embriões somáticos, os dados foram tomados considerando-se o número de clones disponíveis para os testes de campo.

A fim de realizar correlação genética entre as características relativas à capacidade de propagação por embriogênese somática e características de crescimento das plantas em campo, foram realizadas medições das árvores dos clones de Pinus taeda, quanto aos caracteres diâmetro - dap (em cm, medido a 1,30 $\mathrm{m}$ de altura do solo), altura total $-H t$ (em m), volume - $\operatorname{Vol}\left(\mathrm{m}^{3}\right)$ e sobrevivência nas idades de 1, 3 e 4 anos.

O dap foi mensurado com o auxílio de uma fita diamétrica, e a altura foi obtida com o uso do relascópio. Para o cálculo do volume, foi utilizada a fórmula, conforme apresentado a seguir:

Revista Árvore, Viçosa-MG, v.39, n.6, p.1093-1102, 2015 


$$
V o l=\left(3,1416 . \text { dap }^{2} / 4\right) . H t .0,5
$$

em que dap: diâmetro a 1,3 m de altura; e $H t$ : altura total.

A sobrevivência foi avaliada, mediante a contagem do número de árvores vivas por clone no experimento, no momento das medições de dap e $H t(1,3$ e 4 anos de idade).

\subsection{Estimativas de parâmetros genéticos e estatísticos}

As análises foram realizadas pelo procedimento de estimação de componentes de variância (Reml) e de predição de valores genéticos (Blup), usando-se o software Selegen-Reml/Blup (RESENDE, 2002).

As estimativas de parâmetros genotípicos relativas à capacidade de propagação por embriogênese somática (família com embriões somáticos e número de clones em cada família) foram obtidas utilizando o modelo 63 do software Selegen-Reml/Blup (RESENDE, 2007).

Para obtenção dos valores genotípicos das características de crescimento dos testes implantados em campo, foram realizadas análises individuais por local e análise conjunta entre os locais. Na avaliação dos indivíduos reunidos em cada local, foi adotado o modelo 16, implementado no software Selegen-Reml/ Blup (RESENDE, 2007).

As estimativas dos parâmetros na análise conjunta de locais foram realizadas, utilizando-se o modelo linear misto, que inclui o efeito de interação genótipos $\mathrm{x}$ ambientes, o que resultou nos componentes de variância e predição dos valores genéticos, incluindo todos os locais. O modelo estatístico utilizado foi o 52 do software Selegen-Reml/Blup (RESENDE, 2007).

Com os valores genéticos preditos, foram obtidas as correlações genéticas entre os caracteres avaliados e a classificação das famílias, em razão da média dos valores genotípicos preditos, para os clones nas diferentes características.

\section{RESULTADOS}

Considerando as características presença de embriões somáticos nas famílias e o número de clones produzidos para as famílias destinadas ao processo de embriogênese somática, a herdabilidade individual, no sentido amplo entre famílias, foi de magnitude moderada e significativa para as duas características, sendo de 0,44 para a presença de embriões somáticos e de 0,36 para o número de clones somáticos (Tabela 2). A herdabilidade para média de famílias foi de elevada magnitude, tanto para a presença de embriões somáticos (95\%) quanto para o número de clones (92\%), seguindo-se a classificação de Resende (2002).

Essas estimativas de herdabilidade conduzem a expressivas acurácias seletivas na seleção entre famílias, para os caracteres estudados (Tabela 2). Segundo a classificação de Resende e Duarte (2007), as acurácias seletivas encontradas foram de alta magnitude, sendo de $97 \%$ para a presença de embriões somáticos e de $96 \%$ para o número de clones propagados via embriogênese somática (Tabela 2). Verificaram-se altos valores do coeficiente de variação genotípica $\left(\mathrm{CV}_{\mathrm{gi}}\right)$ para presença de embriões somáticos e número de clones propagados via embriogênese somática, acima de 100\% (Tabela 2).

Os coeficientes de variação experimental variaram entre $152 \%$ e $223 \%$, podendo ser considerados muito altos (CAGNELUTTI; STORCK, 2007). Apesar disso, foram obtidas acurácias altas para todos os caracteres avaliados (Tabela 2).

A média geral para a presença de embriões somáticos foi de 0,1 , considerando 35 sementes em cada uma das 65 famílias, ou seja, apenas $10 \%$ das sementes apresentaram formação de embriões somáticos. Entre as sementes das 31 famílias que formaram embriões somáticos, a média foi de 0,22 ou $22 \%$ (Tabela 2 ).

Na Tabela 3, observa-se baixa ou nenhuma correlação genética entre o número de clones propagados via embriogênese somática e as características altura, diâmetro, sobrevivência e volume avaliados aos 4 anos de idade.

Com relação à classificação das famílias em função do número de clones propagados via embriogênese somática, observou-se que a formação de embriões somáticos com competência para a produção de mudas ocorreu de forma heterogênea entre as famílias (Tabela 4). Foi possível identificar famílias com grande número de clones, a exemplo das famílias 25, com 35 clones propagados via embriogênese somática, família 11, com 33 clones propagados via embriogênese somática e família 8, com 21 clones propagados via embriogênese somática, bem como famílias que apresentaram poucos clones propagados via embriogênese somática, a exemplo 
Tabela 2 - Estimativas de parâmetros genotípicos para as características famílias com embriões somáticos e número de clones em razão das famílias de Pinus taeda propagadas via embriogênese somática.

Table 2 - Estimates of genotypic parameters for families characteristics with somatic embryos and clones number according to the families of Pinus taeda propagated via somatic embryogenesis.

\begin{tabular}{ccc}
\hline Parâmetros & Famílias com embriões somáticos & Número de clones \\
\hline $\mathrm{h}^{2} \mathrm{~g}$ & $0,439^{*}(+-0,039)$ & $0,357^{*}(+-0,051)$ \\
$\mathrm{h}^{2} \mathrm{mc}$ & 0,950 & 0,920 \\
$\mathrm{ASC}$ & 0,975 & 0,959 \\
$\mathrm{CVgi} \%$ & 197,712 & 113,446 \\
$\mathrm{CVe} \%$ & 223,705 & 152,167 \\
Média geral & 0,101 & 0,219 \\
\hline
\end{tabular}

$\mathrm{h}^{2} \mathrm{~g}$ : Coeficiente de herdabilidade individual no sentido amplo entre famílias; $\mathrm{h}^{2}$ : Herdabilidade da média de família; ASC: Acurácia na seleção de clones; Média geral: Média geral dos caracteres; CVgi (\%): Coeficiente de variação genotípica; e CVe (\%): Coeficiente de variação experimental.* Significativo pelo teste da razão de verossimilhança a $5 \%$ de significância.

Tabela 3 - Correlação genotípica entre número de clones de Pinus taeda propagados via embriogênese somática $\left(\mathrm{n}^{\circ}\right.$ de clones propagados via ES) e a média do valor genotípico para altura, diâmetro (dap), sobrevivência e volume, em razão das famílias que produziram embriões somáticos aos 4 anos de idade.

Table 3 - Correlation between genotypic number of clones of Pinus taeda propagated via somatic embryogenesis ( $n^{\circ}$. of clones propagated via ES) and the mean genotypic value for height, diameter (dap), survival and volume, depending on the families producing somatic embryos at four years old.

\begin{tabular}{ccccc}
\hline Característica & Altura & dap & Sobrevivência & Volume \\
\hline $\mathrm{N}^{\circ}$ de clones propagados via ES & 0,1309 & 0,0196 & $-0,0047$ & 0,1426 \\
\hline
\end{tabular}

das famílias 5, 10, 14, 15, 16, 18, 27,28, 29 e 30 com apenas um clone cada.

De acordo com a Tabela 5, poucas famílias apresentaram clones entre os 20 melhores nos locais estudados. Das 31 famílias com clones propagados via embriogênese somática, apenas 14 não apresentaram clones entre os 20 melhores. Somente as famílias 1, 8, 13 e 25 puderam ser representadas em todos os sítios, o que pode estar relacionado ao número de clones propagados via embriogênese somática nessas famílias (Tabela 4).

\section{DISCUSSÃ̃O}

Os valores de acurácia apresentados demonstram boa qualidade experimental e confiabilidade na seleção para os caracteres presença de embriões somáticos e número de clones somáticos por família. O coeficiente de variação genotípica $\left(\mathrm{CV}_{\mathrm{gi}}\right)$ demonstra que a seleção é viável, pois há alta variação genotípica entre as famílias estudadas, considerando os caracteres presença de embriões somáticos e número de clones propagados via embriogênese somática. Segundo Resende (2002), coeficiente de variação genotípica acima de $10 \%$ é suficiente para praticar efetiva seleção, portanto é possível a obtenção de ganhos genéticos significativos, neste estudo.

Os resultados apresentados para a herdabilidade, acurácia e coeficiente de variação genotípica indicam que há possibilidade de ganhos genéticos altos, para os caracteres presença de embriões somáticos e número de clones propagados via embriogênese somática, com a seleção de famílias destinadas à embriogênese somática. Resende e Duarte (2007) relataram a possibilidade de obtenção de altas acurácias, mesmo com altos coeficientes de variação experimental, desde que os coeficientes de variação genotípica sejam também altos, como no caso deste trabalho. Segundo alguns estudos, a fase de indução da embriogênese somática é a que apresenta maior possibilidade de ganho genético com a seleção, visando genótipos com alto potencial de propagação via embriogênese somática(PARK et al., 1998; PULLMAN et al., 2003; MACKAY et al., 2006; WALTER et al., 2006).

De acordo com Mackay et al. (2006), a iniciação de culturas embriogênicas de Pinus taeda está sobre forte controle genético, corroborando os resultados deste trabalho. Segundo esses autores, o controle genético diminuiu nas demais fases de produção do embrião somático. Assim, há maior ganho genético

Revista Árvore, Viçosa-MG, v.39, n.6, p.1093-1102, 2015 
Tabela 4 - Classificação das famílias de Pinus taeda em razão do número de clones propagados via embriogênese somática e da média do valor genotípico dos clones em cada família, considerando a avaliação conjunta em todos os ambientes para as características altura $(H t)$, diâmetro $(d a p)$, sobrevivência $(s o b)$ e volume $(v o l)$ aos 4 anos de idade.

Table 4 - Classification of families of Pinus taeda in the number of clones propagated via somatic embryogenesis and the average genotypic value of clones in each family, considering the joint assessment in all environments for characteristics height (Ht), diameter (dap), survival (SOB) and volume (VOL) at four years of age.

\begin{tabular}{|c|c|c|c|c|c|c|c|c|c|c|}
\hline \multirow{2}{*}{ Ordem } & \multirow{2}{*}{ Família } & \multirow{2}{*}{$\begin{array}{l}\mathrm{N}^{\circ} \text { de } \\
\text { clone }\end{array}$} & \multicolumn{8}{|c|}{ Valor genotípico médio para as diferentes famílias em cada característica de avaliação } \\
\hline & & & Família & $H t$ & Família & $d a p$ & Família & $S O B$ & Família & $V O L$ \\
\hline 1 & 25 & 35 & 27 & 6,506 & 5 & 10,732 & 5 & 0,952 & 26 & 0,062 \\
\hline 2 & 11 & 33 & 16 & 6,310 & 26 & 10,515 & 10 & 0,952 & 5 & 0,062 \\
\hline 3 & 8 & 21 & 5 & 6,295 & 11 & 10,513 & 9 & 0,949 & 7 & 0,060 \\
\hline 4 & 24 & 17 & 20 & 6,286 & 7 & 10,493 & 15 & 0,946 & 11 & 0,060 \\
\hline 5 & 1 & 15 & 3 & 6,259 & 20 & 10,403 & 22 & 0,944 & 20 & 0,059 \\
\hline 6 & 6 & 14 & 18 & 6,251 & 31 & 10,358 & 12 & 0,944 & 3 & 0,059 \\
\hline 7 & 12 & 12 & 11 & 6,238 & 3 & 10,353 & 31 & 0,944 & 16 & 0,058 \\
\hline 8 & 4 & 11 & 1 & 6,218 & 16 & 10,266 & 26 & 0,943 & 31 & 0,057 \\
\hline 9 & 2 & 10 & 31 & 6,216 & 18 & 10,238 & 16 & 0,942 & 1 & 0,057 \\
\hline 10 & 13 & 10 & 26 & 6,204 & 1 & 10,216 & 20 & 0,941 & 25 & 0,056 \\
\hline 11 & 17 & 8 & 23 & 6,203 & 25 & 10,167 & 11 & 0,941 & 18 & 0,056 \\
\hline 12 & 31 & 8 & 6 & 6,175 & 27 & 10,147 & 6 & 0,940 & 27 & 0,055 \\
\hline 13 & 3 & 7 & 9 & 6,175 & 6 & 10,075 & 30 & 0,939 & 13 & 0,054 \\
\hline 14 & 21 & 5 & 15 & 6,174 & 9 & 10,071 & 13 & 0,939 & 15 & 0,054 \\
\hline 15 & 22 & 5 & 7 & 6,157 & 13 & 10,069 & 7 & 0,938 & 6 & 0,054 \\
\hline 16 & 7 & 4 & 25 & 6,135 & 15 & 10,069 & 1 & 0,938 & 9 & 0,054 \\
\hline 17 & 23 & 4 & 13 & 6,130 & 10 & 9,974 & 17 & 0,937 & 8 & 0,052 \\
\hline 18 & 20 & 3 & 21 & 6,120 & 14 & 9,940 & 27 & 0,937 & 14 & 0,052 \\
\hline 19 & 9 & 2 & 17 & 6,099 & 8 & 9,918 & 4 & 0,936 & 10 & 0,052 \\
\hline 20 & 19 & 2 & 14 & 6,080 & 30 & 9,810 & 21 & 0,936 & 30 & 0,050 \\
\hline 21 & 26 & 2 & 8 & 6,063 & 12 & 9,764 & 18 & 0,936 & 17 & 0,050 \\
\hline 22 & 5 & 1 & 4 & 6,061 & 4 & 9,716 & 25 & 0,935 & 4 & 0,050 \\
\hline 23 & 10 & 1 & 2 & 6,049 & 17 & 9,713 & 24 & 0,935 & 12 & 0,049 \\
\hline 24 & 14 & 1 & 30 & 6,022 & 22 & 9,657 & 3 & 0,934 & 22 & 0,048 \\
\hline 25 & 15 & 1 & 12 & 6,013 & 2 & 9,594 & 2 & 0,934 & 2 & 0,048 \\
\hline 26 & 16 & 1 & 22 & 5,988 & 28 & 9,538 & 8 & 0,933 & 23 & 0,048 \\
\hline 27 & 18 & 1 & 29 & 5,958 & 24 & 9,292 & 23 & 0,933 & 28 & 0,046 \\
\hline 28 & 27 & 1 & 10 & 5,926 & 23 & 9,284 & 28 & 0,928 & 21 & 0,045 \\
\hline 29 & 28 & 1 & 24 & 5,813 & 29 & 9,249 & 14 & 0,928 & 24 & 0,045 \\
\hline 30 & 29 & 1 & 28 & 5,697 & 21 & 9,225 & 19 & 0,926 & 29 & 0,043 \\
\hline 31 & 30 & 1 & 19 & 5,638 & 19 & 8,171 & 29 & 0,911 & 19 & 0,038 \\
\hline
\end{tabular}

para a capacidade de propagação por embriogênese somática com a seleção de famílias de Pinus taeda com maior predisposição para a iniciação de culturas embriogênicas.

Normalmente, a embriogênese somática em coníferas utiliza como explantes megagametófitos contendo embriões zigóticos imaturos e ocorre por meio de quatro etapas: iniciação, multiplicação, maturação e germinação (PULLMAN et al., 2003). No entanto, a iniciação de culturas embriogênicas é conhecida por estar sob forte controle genético (PARK et al., 1998; LELU et al., 1999;
KLIMASZEWSKA et al., 2001; PULLMAN et al., 2003; MIGUEL et al., 2004; NISKANEN et al., 2004; MACKAY et al., 2006; WALTER et al., 2006). Observa-se forte efeito materno na extrusão do megagametófito e, após a extrusão, efeito genético aditivo (PULLMAN et al., 2003; MACKAY et al., 2006; WALTER et al., 2006). Portanto, a seleção de famílias de Pinus taeda para a propagação via embriogênese somática permite maior iniciação das culturas embriogênicas, o que pode refletir em maior número de famílias propagadas via embriogênese somática e maior número de clones propagados dentro de cada família. 
Tabela 5 - Porcentagem das famílias de Pinus taeda propagadas por embriogênese somática, em razão do número de clones presentes entre os 20 melhores em testes clonais localizados em quatro locais (sítio 1 , sítio 2 , sítio 3 e sítio 4) aos quatro anos após o plantio.

Table 5 - Percentage of family of Pinus taeda propagated by somatic embryogenesis, depending on the number of clones present among the top 20 in clonal tests located at four sites (site 1, site 2, site 3 and site 4) to four years after the planting.

\begin{tabular}{|c|c|c|c|c|c|}
\hline Família & $\mathrm{N}^{\circ}$ de clones & Sítio 1 & Sítio2 & Sítio3 & Sítio4 \\
\hline 1 & 15 & $5 \%$ & $5 \%$ & $15 \%$ & $10 \%$ \\
\hline 2 & 10 & - & - & - & $5 \%$ \\
\hline 3 & 7 & $10 \%$ & $10 \%$ & - & $5 \%$ \\
\hline 4 & 11 & - & $5 \%$ & $5 \%$ & $5 \%$ \\
\hline 5 & 1 & - & - & - & - \\
\hline 6 & 14 & $10 \%$ & $5 \%$ & - & - \\
\hline 7 & 4 & $5 \%$ & - & $5 \%$ & - \\
\hline 8 & 21 & $20 \%$ & $10 \%$ & $15 \%$ & $10 \%$ \\
\hline 9 & 2 & - & $5 \%$ & - & - \\
\hline 10 & 1 & - & - & - & - \\
\hline 11 & 33 & - & - & - & - \\
\hline 12 & 12 & - & - & - & $15 \%$ \\
\hline 13 & 10 & $10 \%$ & $20 \%$ & $15 \%$ & $5 \%$ \\
\hline 14 & 1 & - & - & - & - \\
\hline 15 & 1 & - & $5 \%$ & - & - \\
\hline 16 & 1 & - & - & - & - \\
\hline 17 & 8 & $5 \%$ & - & - & - \\
\hline 18 & 1 & - & - & - & - \\
\hline 19 & 2 & - & - & - & - \\
\hline 20 & 3 & $5 \%$ & - & - & $5 \%$ \\
\hline 21 & 5 & - & - & - & - \\
\hline 22 & 5 & - & - & - & - \\
\hline 23 & 4 & - & - & - & - \\
\hline 24 & 17 & $5 \%$ & $10 \%$ & - & - \\
\hline 25 & 35 & $20 \%$ & $20 \%$ & $35 \%$ & $20 \%$ \\
\hline 26 & 2 & - & - & - & $5 \%$ \\
\hline 27 & 1 & - & - & - & - \\
\hline 28 & 1 & - & - & - & - \\
\hline 29 & 1 & - & - & - & - \\
\hline 30 & 1 & - & - & - & - \\
\hline 31 & 8 & - & $5 \%$ & $5 \%$ & $5 \%$ \\
\hline
\end{tabular}

O efeito materno em culturas embriogênicas de Pinus está ligado à presença do megagametófito haploide durante a iniciação da cultura, o qual é exclusivamente herdado da planta-matriz. Tanto os efeitos genéticos maternos quanto os efeitos genéticos aditivos apresentam diferenças significativas em nível de famílias. Isso indica que a seleção de famílias pode aumentar a eficiência do processo de embriogênese somática (KLIMASZEWSKA et al., 2001; WALTER et al., 2006), corroborando os resultados apresentados neste trabalho.
Os cruzamentos entre os genitores podem ser realizados de maneira a incrementar a capacidade de propagação via embriogênese somática e, como consequência, aumentar o número de famílias propagadas e o número de clones nas famílias. Os cruzamentos entre os progenitores podem ser direcionados selecionando-se a matriz mais favorável para melhorar a frequência de iniciação das culturas embriogênicas (PULLMAN et al., 2003; MACKAY et al., 2006). Segundo Mackay et al. (2006), a taxa de iniciação de culturas embriogênicas de Pinus taeda foi melhorada de 1,5 a 9,2 vezes, alternando a mãe e o pólen do progenitor nos cruzamentos. Assim, a taxa de propagação de clones via embriogênese somática nas famílias de Pinus taeda pode ser melhorada com a seleção de genitores com boa capacidade de iniciação em culturas embriogênicas.

Os resultados referentes à média geral de embriões somáticos formados nas famílias destinadas à embriogênese somática e ao número de embriões somáticos demonstram a heterogeneidade no processo de formação de embriões somáticos nas diferentes famílias de Pinus taeda, indicando que a técnica de embriogênese somática não está plenamente dominada para a espécie.

Segundo Pullman et al. (2003), vários fatores podem estar relacionados à baixa produção de embriões somáticos em Pinus taeada, incluindo baixas taxas de iniciação (muitos genótipos desejáveis são recalcitrantes), baixa taxa de sobrevivência da cultura, baixa ou nenhuma produção de embriões e incapacidade de os embriões somáticos chegarem à plena maturidade, resultando em baixa germinação e reduzido vigor das plântulas somáticas. Em várias espécies de pinheiros, os embriões somáticos apresentam formação morfológica anormal e, quando eles se assemelham aos embriões zigóticos, aparecem em número muito baixo (PULLMAN et al., 2003; CHOUDHURY et al., 2008; CARNEROS et al., 2009; CHAVEZ et al., 2011). Esses fatores têm, como consequência, o número reduzido de genótipos utilizados nos testes clonais e heterogeneidade no processo de formação de embriões somáticos nas diferentes famílias de Pinus taeda.

Outro fator que influencia a taxa de embriogênese somática nas famílias de Pinus taeda são os meios de cultura. Segundo Pullman et al. (2003), não existe, ainda, um meio de cultura capaz de propagar todas as famílias. De acordo com Walter et al. (2006), as 18 famílias de Pinus pinaster utilizadas para a produção de clones via embriogênese somática apresentaram 
diferentes números de embriões somáticos maduros, quando submetidos ao mesmo meio de cultura. Conforme esses autores, o potencial embriogênico varia com o cruzamento entre famílias específicas.

A correlação genética entre os caracteres avaliados demonstra que a seleção, baseada no número de clones propagados via embriogênese somática, não representa a seleção para altura, diâmetro, sobrevivência e volume dos clones aos quatro anos após o plantio. Em abetoda-noruega (Picea excelsa), também não foi observada correlação genética entre número de embriões somáticos e características de crescimento aos sete anos após o plantio em testes clonais conforme estudos de Hogberg et al. (2001) e O'Neilll et al. (2005).

A baixa taxa de produção de clones em algumas famílias pode estar relacionada à recalcitrância dos genótipos à propagação via embriogênese somática. A recalcitrância de genótipos pode restringir os clones ou famílias que podem ser propagadas como embriões somáticos (BECWAR, 1990; PARK et al., 1998). Pode, assim, ocorrer seleção indireta desfavorável para crescimento ou características adaptativas, devido à propagação de genótipos específicos (mais propícios a embriogênese), resultando na perda de famílias ou clones no processo de seleção (PARK et al., 1998; PULLMAN et al., 2003; MACKAY et al., 2006; WALTER et al., 2006).

De acordo com a Tabela 4, as famílias que apresentaram maior número de clones propagados via embriogênese somática não foram as mesmas que mostraram os maiores valores genotípicos médios para altura, diâmetro, sobrevivência e volume, aos 4 anos de idade. Isso já era esperado em razão da baixa correlação genética entre o número de clones propagados via embriogênese somática e as características estudadas.

A família 25 foi a que apresentou o maior número de clones entre os 20 melhores, em todos os locais estudados, o que pode ser reflexo do maior número de clones dessa família propagados via embriogênese somática. Entretanto, observa-se na Tabela 4 que, em média, o valor genotípico dessa família para o volume ficou na décima posição, o que corrobora os resultados apresentados, ou seja, nem sempre a família com maior número de clones propagados via embriogênese somática é a que apresenta os melhores genótipos para características de crescimento e vice-versa.
Grandes avanços foram alcançados no desenvolvimento da embriogênese somática para Pinus taeda, tornando-se método promissor para implementar a silvicultura clonal. No entanto, a frequência de iniciação de culturas embriogênicas, que é altamente variável entre as famílias de Pinus taeda (MACKAY et al., 2006), precisa melhorar, de forma a aumentar o número de clones superiores no campo, para avançar ainda mais na implementação dessa tecnologia em conjunto com o programa de melhoramento genético.

\section{CONCLUSÕES}

Conclui-se que há variabilidade genética e possibilidade de ganhos genéticos para os caracteres presença de embriões somáticos e número de clones propagados via embriogênese somática, com a seleção de famílias de Pinus taeda destinadas à embriogênese somática. A família com maior número de clones propagados via embriogênese somática pode não apresentar os melhores genótipos para características de crescimento, uma vez que houve baixa ou nenhuma correlação genética entre o número de clones propagados via embriogênese somática e as características altura, diâmetro, sobrevivência e volume avaliados aos 4 anos de idade.

\section{AGRADECIMENTOS}

Ao Conselho Nacional de Desenvolvimento Científico e Tecnológico (CNPq) e à Capes (Coordenação de Aperfeiçoamento de Pessoal de Nível Superior) pelo apoio financeiro, e à empresa Klabin S.A por ter cedido a base de dados para realização dos estudos.

\section{REFERÊNCIAS}

ALCANTARA, G. B.; RIBAS, L. L. F.; HIGA, A. R.; RIBAS, K. C. Z. Efeitos do ácido indolilbutírico (AIB) e da coleta de brotações em diferentes estações do ano no enraizamento de miniestacas de Pinus taeda L. Scientia

Forestalis, v.36, n.78, p.151-156, 2008.

ALCANTARA, G. B.; RIBAS, L. L. F.; HIGA, A. R.; ZUFFELLATO-RIBAS, K. C; KOEHLER, H. S. Efeito da idade da muda e da estação do ano no enraizamento de miniestacas de Pinus taeda L. Revista Árvore, v.31, n.3, p.399-404, 2007.

ANDREJOW, G.M.P.; HIGA, A.R. Potencial de enraizamento de miniestacas de Pinus Taeda L. 
provenientes de brotação apical de mudas jovens. Floresta, v.39, n.4, p.897-903, 2009.

BALTUNIS, B.S.; MARTIN, T.A.; HUBER, D.A.; DAVIS, J.M. Inheritance of foliar stable carbon isotope discrimination and third-year height in Pinus taeda clones on contrasting sítios in Florida and Georgia. Tree Genetics \& Genomes, v.4, p.797-807, 2008.

BECWAR, M.R. Initiation of embryogenic cultures and somatic embryo development in loblolly pine (Pinus taeda). Canadian Journal of Research, v.20, n.6, p.810-817, 1990.

BENOWICZ, A.; GROSSNICKLE, S.C.; ELKASSABY, Y.A. Field assessment of Douglasfir somatic and zygotic seedlings with respect to gas exchange, water relations, and frost hardiness. Canadian Journal of Forest Research, v.32,p.1822-1828, 2002.

CAGNELUTTI, A.F.; STORCK, L. Estatísticas de avaliação da precisão experimental em ensaios de cultivares de milho. Pesquisa Agropecuária Brasileira, v.42, n.1, p.17-24, 2007.

CARNEROS, E.;CELESTINO, C.;

KLIMASZEWSKA, K.; PARK, Y. S.; TORIBIO, M.; BONGA, J.M. Plant regeneration in Stone pine (Pinus pinea L.) by somatic

embryogenesis. Plant Cell, v.98, n.1, p.165$178,2009$.

CHAVEZ, L. A.;FLINN, B. S.;EGERTSDOTTER, U.; SEDEROFF, R. Initiation of somatic embryogenesis from immature zygotic embryos of Oocarpa pine (Pinus oocarpa Schiede ex Schlectendal). Tree Physiology, v.31, n.5, p.539-554, 2011.

CHOUDHURY, H.; KUMARIA, S.; TANDON, P. Induction and maturation of somatic embryos from intact megagametophyte explants in Khasi pine (Pinus kesiya Royle ex. Gord.). Current Science, v.95, n.10, p.1433-1438, 2008.

CYR, D. R.; LAZAROFF, W. R.; GRIMES, S. M. A.; QUAN, Q. Q.; BETHUNE, T. D.; DUNSTAN, D. I.; ROBERTS, D. R. Cryopreservation of interior spruce (Picea glauca engelmanni complex) embryogenic cultures. Plant Cell Reports, v.13, 10, p.574-577, 1994.
DEAN, C.A. Genetic parameters of somatic clones of coastal douglas-fir at $51 / 2$-years across Washington and Oregon, USA. Silvae Genetica, v.57, n.4/5, p.269-275, 2008.

GROSSNICKLE, S.C.; FOLK, R. Stock quality assessment of a somatic interior spruce seedlot. Canadian Journal of Forest Research, v.22, p.197-202, 2005.

HOGBERG, K. A.; BOZHKOV, P. V.; GNONNOOS, R.; ANXOLO, S.V. Critical factors affecting ex vitro performance of somatic embryo plants of Picea abies. Scandinavian Journal of Forest Research, v. 16, n.4, p.295-304, 2001.

KLABIN. Plano de manejo florestal 2011: resumo público Telêmaco Borba - PR. Telêmaco Borba: 2011. 24p.

KLABIN. Plano de manejo florestal: resumo público Santa Catarina. Otacílio Costa: 2009. 12p.

KLIMASZEWSKA, K.; PARK, Y. S.; OVERTON, C.; MACEACHERON, I.; BONGA, J. M.

Optimized somatic embryogenesis in Pinus strobus L. In Vitro Cell Development Biol-Plant, v.37, p.392-399, 2001.

LELU, M. A.; BASTIEN, C.; DRUGEAULT, A.; GOUEZ, M. L.; KLIMASZEWSKA, K. Somatic embryogenesis and plantlet development in Pinus sylvestris and Pinus pinaster on medium with and without growth regulators. Physiologia Plantarum, v.105, n.4, p.719-728, 1999.

MACKAY, J. J.; BECWAR, M R.; PARK, Y. S.; CORDERRO, J. P.; PULLMAN, G. S. Genetic control of somatic embryogenesis initiation in loblolly pine and implications for breeding. Tree Genetics and Genomes, v.2, n.1, p.1-9, 2006.

MALABADI, R. B.; NATARAJA, K.; KUMAR, S. V.; MULGUND, G. S. Journey of a single cell to a plantlet via in vitro cloning mature trees of conifers. Research in Biotechnology, v.2, n.6, p.1-7, 2011

MIGUEL, C.; GONCALVES, S.; TERESO, S.; MARUM, L.; OLIVEIRA, M. M. Somatic embryogenesis from 20 open-pollinated seed families of Portuguese plus trees of maritime pine. Plant Cell Tissue Organic Culture, v.76, p.121-130, 2004.

Revista Árvore, Viçosa-MG, v.39, n.6, p.1093-1102, 2015 
NISKANEN, A. M.; LU, J.; SEITZ, S.; KEINONEN, K.; VON WEISSENBERG, K.; PAPPINEN, A. Effect of parent genotype on somatic embryogenesis in Scots pine (Pinus sylvestris). Tree Physiologie, v.24, n.11, p.1259-1265, 2004.

O'NEILLL, G. A.; RUSSELL, J. H.; HOOGE, B. D.; OTT, P. K.; HAWKINS, C. B. D. Estimating gains from genetic tests of somatic emblings of interior spruce. Forest Genetics, v.12, n.1, p.57-66, 2005.

PARK, Y.S.; BARRETT, J.D.; BONGA, J.M. Application of somatic embryogenesis in highvalue clonal forestry: Deployment, genetic control, and stability of cryopreserved clones. In vitro Cellular Developmental Biology Plant, v.34, p.231-239, 1998.

PARK, Y.S. Implementation of conifer somatic embryogenesis in clonal forestry: technical requirements and deployment considerations. Annals of Forest Science, v.59, p.651-656, 2002.

PULLMAN, G.S.; BUCALO, K. Pine somatic embryogenesis using zygotic embryos as explants. Methods in Molecular Biology, v.710, p.267-291, 2011.

PULLMAN, G.S.; CHOPRA, R.; CHASE, K.M. Loblolly pine (Pinus taeda L.) somatic embryogenesis: improvements in embryogenic tissue initiation by supplementation of medium with organic acids, vitamins $\mathrm{B}_{12}$ and E. Plant Science, v.170, p.648-658, 2006.

PULLMAN, G. S.; JOHNSON, S.; PETER, G.; CAIRNEY, J.; XU, N. Improving loblolly pine somatic embryo maturation: comparison of somatic and zygotic embryo morphology, germination, and gene expression. Plant Cell Reports, v.21, p.747-758, 2003.

RESENDE, M.D.V.; DUARTE, J.B. Precisão e controle de qualidade em experimentos de avaliação de cultivares. Pesquisa

Agropecuária Tropical, v.37, n.3, p.182-194, 2007.

RESENDE, M.D.V. Genética biométrica e estatística no melhoramento de plantas perenes. Brasília: Embrapa Informação Tecnológica; Colombo: Embrapa Florestas, 2002. $975 \mathrm{p}$.

RESENDE, M.D.V. Selegen - Reml/ Blup:Sistema estatístico e Seleção genética computadorizada via modelos lineares mistos. Colombo: Embrapa Florestas, 2007.361p.

SUTTON, B. Commercial delivery of genetic improvement to conifer plantations using somatic embryogenesis. Forest Science, v.59, p.657$661,2002$.

WAHID, N.; RAINVILLE, A.; LAMHAMEDI, M. S.; MARGOLIS, H. A.; BEAULIEU, J.; DEBLOIS, J. Genetic parameters and performance stability of white spruce somatic seedlings in clonal tests.

Forest Ecology and Management, v.270, n.1, p.45-53, 2012.

WALTER, M.A.L.; CARDOU, M.B.;

KLIMASZEWSKA, K. Simplified and improved somatic embryogenesis for clonal propagation of Pinus pinaster (Ait.). Plant Cell Reports, v.26, p.767-776, 2006. 